\title{
Randomised controlled trial of zinc supplementation in malnourished Bangladeshi children with acute diarrhoea
}

\author{
S K Roy, A M Tomkins, S M Akramuzzaman, R H Behrens, R Haider, D Mahalanabis, \\ G Fuchs
}

\begin{abstract}
Objective-To evaluate the impact of zinc supplementation on the clinical course, stool weight, duration of diarrhoea, changes in serum zinc, and body weight gain of children with acute diarrhoea.

Design-Randomised double blind controlled trial. Children were assigned to receive zinc $(20 \mathrm{mg}$ elemental zinc per day) containing multivitamins or control group (zinc-free multivitamins) daily in three divided doses for two weeks.

Setting-A diarrhoeal disease hospital in
\end{abstract} Dhaka, Bangladesh.

Patients-111 children, 3 to 24 months old, below $76 \%$ median weight for age of the National Center for Health Statistics standard with acute diarrhoea. Children with severe infection and/or oedema were excluded.

Main outcome measures-Total diarrhoeal stool output, duration of diarrhoea, rate of weight gain, and changes in serum zinc levels after supplementation.

Clinical Sciences

Division, International Centre for Diarrhoeal Diseases Research, Dhaka, Bangladesh S K Roy

S M Akramuzzaman

R Haider

D Mahalanabis

G Fuchs

Centre for

International Child

Health, Institute of

Child Health, London

A $M$ Tomkins

Clinical Nutrition

Unit, Department of

Clinical Sciences,

London School of

Hygiene and Tropical

Medicine, London

R H Behrens

Correspondence to: Dr S K Roy, International

Centre for Diarrhoeal

Disease Research,

Bangladesh, GPO Box 128 ,

Mohakhali, Dhaka 1000,

Bangladesh.

Accepted 13 June 1997 $<0.001$ ) during two weeks of supplementation, and better mean weight gain (120 $v 30$ $g, p<0.03)$ at the time of discharge from hospital.

Conclusions-Zinc supplementation is a simple, acceptable, and affordable strategy which should be considered in the management of acute diarrhoea and in prevention of growth faltering in children specially those who are malnourished. (Arch Dis Child 1997;77:196-200)

Keywords: zinc supplementation; acute diarrhoea; weight gain; malnutrition
Diarrhoea remains a major cause of morbidity and mortality in less developed countries. ${ }^{1} \mathrm{~A}$ significant proportion of children who suffer from diarrhoea are malnourished, and malnutrition is associated with increased severity and duration of diarrhoea in such children. ${ }^{2-4}$ These malnourished children are often reported to have associated micronutrient deficiencies. ${ }^{5-7}$ An association between zinc deficiency and impaired growth has also been observed. Furthermore, zinc is important in the control of growth of the intestinal mucosa. ${ }^{8}$ Zinc supplementation improves the transport of water and electrolytes across the intestinal mucosa in experimental zinc deficiency. ${ }^{9-11}$ Severe zinc deficiency syndrome in humans, known as acrodermatitis enteropathica, responds to treatment with oral zinc supplements. ${ }^{12}$ Castillo-Duran et al have reported that daily losses of zinc in the intestinal fluid during acute diarrhoea are as high as 159 $\mu \mathrm{g} / \mathrm{kg} /$ day, compared with $47 \mu \mathrm{g}$ in control children. ${ }^{13}$ Children with marginal nutritional status are at significant risk of developing zinc depletion with an episode of diarrhoea. Zinc is a constituent of more than 100 metalloenzymes and is essential for growth, protein synthesis, epithelial repair, and synthesis of RNA and DNA. ${ }^{14}$ Hence there are many reasons why zinc deficiency could affect intestinal function. Zinc has marked effects on $\mathrm{T}$ cell function ${ }^{15}$ and zinc supplementation improves immunity, ${ }^{16} 17$ which may reduce the severity of diarrhoea by limiting growth and multiplication of diarrhoeal pathogens in the intestine. We therefore hypothesised that zinc deficiency is prevalent in malnourished children with diarrhoea and that zinc supplementation would reduce the severity and duration of diarrhoea.

\section{Methods}

DESIGN

A double blind, randomised, controlled clinical trial was conducted in children with diarrhoea of less than three days' duration who were admitted to the International Centre for Diarrhoeal Disease Research, Bangladesh. Children aged between 3 and 24 months were eligible for the study provided they had no systemic infection or oedema, and their weight was below the 76th centile of weight for age according to the 
National Center for Health Statistics (NCHS) standard $^{18}$ (by Gomez classification, protein energy malnutrition grades II and III are included).

SAMPLE SIZE

The sample size was determined on the assumption that zinc supplementation would decrease intestinal fluid losses at least by $20 \%$ and reduce the duration by $20 \%$. The estimation of sample size was performed according to Kirkwood, ${ }^{19}$ taking the probability at the $5 \%$ level and assuming a power of $80 \%$.

A block randomisation procedure was performed using a random table to assign eligible patients equally to a treatment group receiving zinc acetate with multivitamin syrup or the control group receiving only multivitamin syrup of the same basic ingredients (prepared by Square Pharmaceutical Co, Bangladesh). The syrups were identical in appearance and flavour and were packaged in identical containers. Randomised patient numbers were labelled on the bottles to maintain the double blind design. Fifty seven children received zinc and 54 received the multivitamin syrup.

CLINICAL PROCEDURES

On admission, dehydration was assessed using World Health Organisation (WHO) guidelines ${ }^{20}$ and corrected within four hours with either intravenous polyelectrolyte solution or WHO/Unicef oral rehydration solution. Body weight after rehydration was measured with a scale having a precision of $20 \mathrm{~g}$ on the day of admission and daily thereafter between 9 and 10 am. Supine length was measured on a locally constructed length board to a precision of $1 \mathrm{~mm}$. Nutritional status was expressed as a per cent of the median NCHS standard. Shorter children were defined as less than $95 \%$ height for age. ${ }^{21}$ Serum zinc concentrations were considered low if they were below 14 $\mu \mathrm{mol} / 1$ (as found in malnourished and zinc deficient children). ${ }^{22}$

To examine a possible relation between serum zinc and diarrhoeal or nutritional outcome, children with hypozincaemia on admission were considered to be zinc deficient. However, as the number of children with very low serum zinc concentrations (below 10 $\mu \mathrm{mol} / \mathrm{l})$, was very small, the 66 th centile value for serum zinc was taken as the lower cut off point for comparing the effect of zinc supplementation among the more zinc deficient children.

A normal hospital diet (milk/cereal/liquid diet, appendix 1) was given ad libitum and breast feeding was encouraged. Zinc was given as $20 \mathrm{mg}$ elemental zinc per day in three divided doses for a period of two weeks in a multivitamin syrup. This was prepared by Square Pharmaceuticals Co, Bangladesh, and contained in each $5 \mathrm{ml}$ : elemental zinc $6.5 \mathrm{mg}$, vitamin A 3000 IU, vitamin D 600 IU, vitamin B-1 $1.2 \mathrm{mg}$, riboflavin $2.0 \mathrm{mg}$, vitamin B-6 0.6 $\mathrm{mg}$, nicotinamide $6.0 \mathrm{mg}$, and calcium $\mathrm{d}$-pantothenate $6.0 \mathrm{mg}$. One millilitre of zinc syrup contained $1.3 \mathrm{mg}$ of elemental zinc. The control group received the same multivitamin syrup but without zinc. The syrup was given by the mothers under direct continuous supervision of nurses during the hospital inpatient stay and by community health workers on alternate day home follow up visits.

LABORATORY INVESTIGATIONS

Blood samples were obtained on admission, after correction of dehydration, and at the end of the supplementation and were stored at $-20^{\circ} \mathrm{C}$. Urine was collected separately from stool using adhesive single use paediatric urine collection bags. Stool was collected in a preweighed container beneath a cholera cot and measured every eight hours on a sensitive scale to the nearest $1 \mathrm{~g}$. Clinical recovery from diarrhoea was defined as the passage of a soft formed stool. Serum zinc was measured using an atomic absorption spectrophotometer (Pye Unicam, SP9) and serum retinol by high performance liquid chromatography (HPLC, Waters 510, USA). Enteric pathogens were isolated according to the WHO manual for laboratory investigations of acute enteric infections. $^{23}$ Informed written consent was obtained from the parents of all patients before inclusion of the children in the study. The study was approved by the ethics review committee of the International Centre for Diarrhoeal Disease Research.

STATISTICAL ANALYSIS

Data were recorded on questionnaires and transferred to coding sheets. Data cleaning, validation, and analyses were performed using SPSS/PC+, EPISTAT, and NCHS anthropometric software. Student's unpaired and paired $t$ tests were used on normally distributed data and the non-parametric Mann-Whitney test and Wilcoxon's matched paired tests were used for stool weight and body weights of malnourished and zinc deficient children respectively, where the distribution was skewed. Statistical significance was considered to be at the 5\% probability level.

\section{Results}

Fifty four subjects were allocated to control group not receiving zinc but only multivitamin syrup, and 57 subjects received zinc supplementation with multivitamins. The oral zinc supplementation was palatable and well accepted by the children and without any apparent complications.

Diarrhoeal pathogens were isolated in $67 \%$ of the children. Single infections were noted with rotavirus $(25 \%)$, enteropathogenic Escherichia coli (7\%), enterotoxigenic E coli $(6 \%)$, Vibrio cholerae (2\%), and shigella or campylobacter spp $(7 \%)$. Fifteen per cent of the children had a mixed infection. The distribution of pathogens was similar between the zinc supplemented and placebo groups.

BASELINE COMPARISON

On admission, the mean values of the general characteristics of the children of the control group were comparable with those of the zinc supplemented group, for example: age, $11 v 11$ months; per cent of median weight for age, 67 
Table 1 Impact of zinc supplementation on stool output in children during acute diarrhoea

\begin{tabular}{llll}
\hline & \multicolumn{4}{l}{ Total stool weight/kg body weight, median (range) } & \\
\cline { 2 - 4 } & Placebo & Zinc supplemented & p Value $^{*}$ \\
\hline All children & $329(32-1464) \mathrm{n}=37$ & $238(35-2416) \mathrm{n}=37$ & 0.06 \\
Height/age $<95 \%$ & $326(31-1460) \mathrm{n}=33$ & $239(33-2496) \mathrm{n}=37$ & $<0.04$ \\
Serum zinc $(<14 \mu \mathrm{mol} / \mathrm{l})$ & $326(99-1464) \mathrm{n}=25$ & $279(43-2416) \mathrm{n}=30$ & $<0.049$ \\
\hline
\end{tabular}

^Mann-Whitney U test.

Table 2 Impact of zinc supplementation on duration of diarrhoea in days. Values are mean (95\% confidence interval)

\begin{tabular}{lllr}
\hline & Placebo & Zinc & p Value \\
\hline All children & $5.80(4.93$ to 5.84$) \mathrm{n}=37$ & $5.0(4.16$ to 5.84$) \mathrm{n}=37$ & 0.33 \\
Serum zinc $<14 \mu \mathrm{mol} / 1$ & $6.0 \quad(4.96$ to 7.0$) \mathrm{n}=25$ & $4.7(3.92$ to 5.48$) \mathrm{n}=30$ & $<0.04$ \\
Wasted $<80 \%$ weight/height & $5.8(4.53$ to 7.07$) \mathrm{n}=18$ & $4.9(3.72$ to 6.07$) \mathrm{n}=11$ & 0.35 \\
Stunted $<95 \%$ height/age & $6.0 \quad(5.0$ to 6.94$) \mathrm{n}=33$ & $5.0(4.16$ to 5.84$) \mathrm{n}=37$ & 0.13 \\
\hline
\end{tabular}

^Student's $t$ test.

Table 3 Impact of zinc supplementation on weight gain and serum zinc levels during management of acute diarrhoea. Values are mean (95\% confidence interval)

\begin{tabular}{lllc}
\hline & \multicolumn{2}{l}{ Body weight $(\mathrm{kg})$} & \\
\cline { 2 - 4 } & On admission & At discharge & $p$ Value $^{\star}$ \\
\hline Placebo $(\mathrm{n}=54)$ & $6.43(6.1$ to 6.7$)$ & $6.46(6.2$ to 6.8$)$ & 0.68 \\
Zinc $(\mathrm{n}=57)$ & $6.19(5.9$ to 6.5$)$ & $6.31(6.0$ to 6.6$)$ & 0.03 \\
& Serum zinc $(\mu m o l / l)$ & & \\
\cline { 2 - 4 } & On admission & After 2 weeks & 0.63 \\
& $12.6(11.0$ to 14.1$)$ & $12.3(11.3$ to 13.3$)$ & $<0.0001$ \\
\hline Placebo $(\mathrm{n}=37)$ & $11.2(10.4$ to 12.0$)$ & $13.6(12.5$ to 14.7$)$ & \\
Zinc $(\mathrm{n}=37)$ & & &
\end{tabular}

v 67; height/age, 92 v 92; weight/height, $81 v$ 81 ; mid upper arm circumference, 11.6 v 11.3 $\mathrm{cm}$; serum zinc, $12.6 v 11.2 \mu \mathrm{mol} / \mathrm{l}$; duration of diarrhoea before entry into the study, $2.6 v 2.8$ days; proportion of shorter children, $78 \% v$ $87 \%$; proportion of wasted children, $48 \% v$ $39 \%$; proportion of children having lower serum zinc (as defined above), $74 \%$ v $75 \%$. The distribution of male and female subjects were also comparable between the control and zinc supplemented group: M/F, 31/23 $v 33 / 24$.

The patients were followed after the discharge from the hospital to ensure completeness of their two week zinc supplementation. Sixteen children in the placebo group and 20 in the zinc supplemented group could not be located because they migrated following a flood in Dhaka city, the catchment area of the study patients. Hence analysis for the time to recovery and diarrhoeal stool weight was restricted to those whose second blood sample

Table 4 Impact of zinc supplementation on weight gain in stunted, wasted, and zinc deficient children. Values are median (range)

\begin{tabular}{|c|c|c|c|}
\hline & $\begin{array}{l}\text { On admission } \\
\text { (weight in } \mathrm{kg} \text { ) }\end{array}$ & $\begin{array}{l}\text { At discharge } \\
\text { (weight in } \mathrm{kg} \text { ) }\end{array}$ & $p$ Value $^{*}$ \\
\hline \multicolumn{4}{|c|}{$\begin{array}{l}\text { Height for age }<95 \% \text { of } \\
\text { median NCHS }\end{array}$} \\
\hline Placebo $(\mathrm{n}=42)$ & $6.28(4.52-8.80)$ & $6.27(4.50-8.22)$ & 0.7 \\
\hline $\operatorname{Zinc}(\mathrm{n}=50)$ & $6.08(4.30-8.52)$ & $6.20(4.20-8.80)$ & 0.006 \\
\hline \multicolumn{4}{|c|}{$\begin{array}{l}\text { Weight for height }<80 \% \text { of } \\
\text { median NCHS }\end{array}$} \\
\hline Placebo $(\mathrm{n}=26)$ & $6.65(4.68-9.16)$ & $6.77(5.02-9.86)$ & 0.1 \\
\hline Zinc $(\mathrm{n}=22)$ & $5.90(4.85-8.80)$ & $6.0 \quad(5.10-8.80)$ & 0.08 \\
\hline \multicolumn{4}{|c|}{ Serum zinc $<14 \mu \mathrm{mol} / 1$} \\
\hline Placebo $(\mathrm{n}=40)$ & $6.31(4.52-9.16)$ & $6.23(4.50-9.86)$ & 0.49 \\
\hline Zinc $(n=43)$ & $6.04(4.22-8.80)$ & $6.20(4.20-8.80)$ & $<0.05$ \\
\hline
\end{tabular}

^Wilcoxon's matched pair test. could be obtained, to ensure that they had received two weeks of supplementation.

CLINICAL OUTCOME

The median total diarrhoeal stool output (g/kg/ day) was $28 \%$ less in the zinc supplemented group as a whole $(p=0.06)$. Zinc supplementation reduced median stool weight (279 $v 326$ $\mathrm{g} / \mathrm{kg}, \mathrm{p}<0.04)$ in those children who had lower serum zinc $(<14 \mu \mathrm{mol} / \mathrm{l})$ on admission. There was reduction in median total diarrhoeal stool output with zinc supplementation in the shorter children ( $<95 \%$ height/age) compared to similar children receiving placebo (279 $v 326 \mathrm{~g} / \mathrm{kg}, \mathrm{p}$ $<0.049$ ) (table 1).

The duration of diarrhoea was shorter by $14 \%$ (NS) with zinc supplementation among the entire group of children. Children with a lower serum zinc $(<14 \mu \mathrm{mol} / \mathrm{l})$ achieved a $22 \%$ reduction $(\mathrm{p}<0.04)$ in the duration of diarrhoea with zinc supplementation (table 2). No such difference in duration among the stunted or wasted children was found.

Weight gain at discharge and improved serum zinc levels were noted in the zinc supplemented children. The zinc supplemented group had gained in mean body weight (6.31 v6.19 kg, $\mathrm{p}=0.03$ ) but there was no gain in the placebo group $(6.46 v 6.43 \mathrm{~kg}, \mathrm{p}=0.68)$. The control group showed a slight reduction in mean serum zinc $(12.6 \vee 12.3 \mu \mathrm{mol} / \mathrm{l}, \mathrm{p}=$ 0.63 ), whereas the supplemented group had a significant increase in mean serum zinc (11.2 $v$ 13.6 $\mu \mathrm{mol} / 1, \mathrm{p}<0.001$ ) (table 3).

\section{NUTRITIONAL OUTCOME}

The body weight of the zinc supplemented stunted and wasted children increased by the time of recovery from diarrhoea. The change was significant in the supplemented stunted group (median $6.20 \mathrm{~kg}$ from $6.08 \mathrm{~kg}, \mathrm{p}<$ 0.006) compared with their counterparts in the control group (6.27 kg from $6.28 \mathrm{~kg}, \mathrm{p}=0.7)$. Similarly in children who had lower serum zinc, the supplemented group had a significant increase in body weight $(6.20 \mathrm{~kg}$ from $6.04 \mathrm{~kg}$, $\mathrm{p}=0.05)$ compared to the control group (6.23 $\mathrm{kg}$ from $6.31 \mathrm{~kg}, \mathrm{p}=0.49$ ) (table 4 ).

\section{Discussion}

Our study examined several aspects of zinc supplementation. Zinc deficiency in children with diarrhoea occurs as a result of increased zinc loss in the stool ${ }^{13}$ together with reduced dietary intake. Many studies have stressed that serum zinc is not a good indicator of overall zinc status. ${ }^{24}$ Yet we have been able to show clearly that our group of children with moderate to severe malnutrition showed a rise in serum zinc after supplementation, even when they were suffering from acute diarrhoeal illness. On the other hand, the group given multivitamins alone did not show any improvement in serum zinc concentrations. This result suggests that serum zinc does have value as an indicator of zinc nutrition. However, we do not know whether this rise in serum zinc is maintained. The significant rise in serum zinc following zinc supplementation suggested an improvement in zinc status. We feel that the 
quantity of zinc given, which was double the recommended nutrient intake, was adequate to allow a physiological effect despite the known reduction in absorption during diarrhoea.

The results of zinc supplementation might have been even greater if the control group had not received multivitamin syrup. However, the children were malnourished, and hence multivitamin supplementation during a diarrhoeal episode was appropriate. The WHO has suggested that children below 1 year of age are given 100000 IU vitamin A at six month intervals, with an additional dose during diarrhoea. Our patients were given 126000 IU vitamin A during their diarrhoeal episode over a 2 week period in both study groups. During diarrhoea, the absorption of vitamin $\mathrm{A}$ is significantly reduced, while the requirement in malnourished children is increased; hence the dose given to our children should have been adequate. The cost of the zinc and multivitamin syrup was $£ 0.33$ (US $\$ 0.50$ ) per child for a two week course. In Bangladesh and most developing countries, a large majority of children suffer from malnutrition and they contract about three to four episodes of diarrhoea in a year. The study was conducted in a malnourished group of children who are likely to be depleted of endogenous zinc from earlier diarrhoeal episodes and low dietary intake.

As the number of children with any specific enteric pathogen was small, we analysed the results from all the children without stratifying them according to the type of pathogenic organism, assuming that with random allocation patients with particular pathogens would be equally distributed in the two groups. In doing this, we recognise that those with a limited response to zinc might dilute the effect of zinc on those with mucosal damage. None the less zinc supplementation reduced net fluid loss, as indicated by reduced stool weight among the shorter children and in those with lower serum zinc levels.

A recently published epidemiological study from India by Sazawal et al showed a $7 \%$ reduction in the proportion of episodes lasting more than seven days if zinc supplementation was given within three days of the onset of diarrhoea ${ }^{25}$ and the authors also documented a greater reduction $(39 \%)$ in the duration of diarrhoea among the shorter children. The limitation of that study was that stool was not quantitated and was not under continuous observation for accurate recording of recovery. Home visits were made and a history of diarrhoea was taken from the caretaker of the child, whereas in our study there was 24 hour observation and meticulous weighing of stool output during the period of hospital management, while time to recovery was confirmed by direct observation. The study by Sazawal et al did not document the reduction in fluid loss during diarrhoea. It is noteworthy that the stool output of our study children varied over a wide range, perhaps because of the different stool pathogens. Our previous experimental animal studies ${ }^{8-10}$ showed that zinc supplementation in zinc deficient rats resulted in an increase in

\section{Key messages}

$20 \mathrm{mg}$ of daily zinc supplementation reduced diarrhoeal stool in shorter children

- Zinc reduced diarrhoeal stool in those with low serum zinc

- Zinc reduced duration of diarrhoea in children with low serum zinc

- Zinc increased body weight of children during acute diarrhoeal episode

- Malnourished children are likely to benefit more from zinc supplementation

mucosal mass and in absorption of water and sodium. It has also been well demonstrated that zinc supplementation improves the mucosal lesion in patients with acrodermatitis enteropathica. ${ }^{26}{ }^{27}$

Zinc deficiency in children has been associated with dwarfism and it is well recognised that a chronic zinc deficient state may be reflected in slow growth or height faltering in children. Shorter children may thus be zinc deficient and this may explain why this group had a better response to zinc supplementation. We have previously reported a significant improvement in mucosal integrity in response to zinc supplementation, as assessed by measurements of intestinal permeability. ${ }^{28}$ It was reported in an earlier study from India that children receiving $40 \mathrm{mg}$ of elemental zinc daily during acute diarrhoea responded with a shorter duration of diarrhoea than a control group. ${ }^{29}$ The response was linked to a significantly earlier recovery in the children who had lower rectal zinc concentration and were considered to be a zinc deficient subgroup. Improved integrity of the small intestinal mucosa, which we showed earlier, ${ }^{28}$ may partially explain the improved fluid absorption reflected in reduced stool output and earlier recovery from diarrhoea. In Mexican preschool children zinc supplementation reduced diarrhoeal morbidity. ${ }^{30}$

Another possibility is that zinc supplementation may promote the rapid clearance of diarrhoeal pathogens from the intestine through improved immunity. Zinc supplementation is known to improve cell mediated immunity and it increases salivary secretory IgA in malnourished children. ${ }^{16}{ }^{31}$ Clearance of intestinal parasites such as Strongyloides ratti in zinc deficient rats occurred significantly earlier and more efficiently after zinc supplementation. ${ }^{32}$ Zinc supplementation has also been found to reduce the duration of infection with rhinovirus in elderly patients. ${ }^{33}$ It may be assumed that zinc inhibits viral activity but it is difficult to say whether zinc supplementation reduces diarrhoea because of an effect on viruses such as rotavirus, which was present in about one third of our subjects. It is known that diarrhoea may cause growth faltering in children ${ }^{34}$ by a variety of mechanisms including decreased dietary intake, malabsorption, and loss of endogenous nutrients, and altered metabolism.

The rate of catch up weight gain in our children was greater in those receiving zinc than 
in the control group. This might be a result of better absorption of nutrients and increased protein synthesis after zinc supplementation. Zinc supplementation of malnourished Jamaican children during nutritional rehabilitation was associated with increased lean tissue synthesis. $^{35}$ Zinc supplementation also promoted an increased weight gain velocity of 8.8 $\mathrm{g} / \mathrm{kg} /$ day among children recovering from severe malnutrition in Bangladesh. ${ }^{36}$ The effect of zinc on diarrhoeal pathogens could reduce loss of endogenous zinc, electrolytes, and water.

In conclusion, our study shows overall weight gain in children with zinc supplementation, an increase in serum zinc in the face of acute diarrhoea, and significant benefit in reduction of the duration of diarrhoea and diarrhoeal stool output among the children who had linear growth faltering and who had lower serum zinc values.

We propose that zinc supplementation is a simple, acceptable, and affordable strategy which should be considered in the management of acute diarrhoea and prevention of growth faltering in children, specially those who are malnourished.

This research was supported by the Wellcome Trust (UK) and the International Centre for Diarrhoeal Disease Research, Bangladesh (ICDDR,B). The ICDDR,B is supported by countries and agencies which share its concern for the health problems of developing countries. Current donors include: the aid agencies of the Governments of Australia, Bangladesh, Belgium, Canada, Japan, The Netherlands, Norway, Saudi Arabia, Sri Lanka, Sweden, Switzerland, the United Kingdom and the United States; international organisations including Arab Gulf United States; international organisations including Arab Gulf Fund, Asian Development Bank, the European Union, the United Nations Children's Fund (Unicef), the United Nations
Development Programme (UNDP), and the World Health Development Programme (UNDP), and the World Health Organisation (WHO); private foundations including Aga Khan
Foundation, Child Health Foundation (CHF), Ford FoundaFoundation, Child Health Foundation (CHF), Ford Founda-
tion, Population Council, Rockefeller Foundation, Thrasher tion, Population Council, Rockefeller Foundation, Thrasher Foundation, and the George Mason Foundation; and private organisations including East West Inc, Helen Keller International, International Atomic Energy Agency, Lederle Praxis, New England Medical Center, Procter and Gamble, RAND Corporation, Social Development Centre of the Philippines, the Swiss Red Cross, Johns Hopkins University, the University of Alabama at Birmingham, UCB Sidac, Wander AG, and others. We are grateful to Professor R Eeckels, Ex-Director ICDDR,B for his active interest in the study, and to Drs Iqbal Kabir and $M$ A Salam for their suggestions on the manuscript. We acknowledge Mrs Jarin Sultana, Azmira Begum, Sabira Islam, and Quazi Eliza Islam for their careful work during the study, the members of the Clinical Research Centre for their cooperation, and $\mathrm{Mr} \mathrm{M}$ of the Clinical Research Centre for their cooperation, and $\mathrm{Mr} M$ chemical analysis. We acknowledge Mr K M Rafique for his help in preparing this manuscript.

Appendix 1

Composition of diet for acute diarrhoea patients (per litre). Low lactose milk based diet

\begin{tabular}{ll}
\hline Milk powder & $35 \mathrm{~g}$ \\
Rice powder & $30 \mathrm{~g}$ \\
Sugar & $25 \mathrm{~g}$ \\
Oil & $20 \mathrm{ml}$ \\
Sodium chloride & $1 \mathrm{~g}$ \\
Water up to & $1 \mathrm{litre}$ \\
Energy & $2800 \mathrm{~kJ}(670 \mathrm{kcal})$ \\
Protein & $17 \mathrm{~g}$ \\
Elemental zinc & $1.4 \mathrm{mg}$ \\
\hline
\end{tabular}

1 Snyder JD, Merson MH. The magnitude of the global problem of acute diarrhoeal disease: a review of active

2 Tomkins A. Nutritional status and severity of diarrhoea among preschool children in rural Nigeria. Lancet 1981;i: among

3 Black RE, Brown KH, Becker S. Malnutrition is the determining factor in diarrhoeal duration, but not incidence among young children in a longitudinal study in rura Bangladesh. Am f Clin Nutr 1984;39:87-94.
4 Ahmed K, Hasan N. Nutritional survey of rural Bangladesh 1981-1982. Dhaka: University of Dhaka, Bangladesh, $1981-1986$.

5 Khanum S, Alam AN, Anowar I, Akbar-Ali M, Rahaman MM. Effect of zinc supplementation on the dietary intake and weight gain of Bangladeshi children recovering from protein energy malnutrition. Eur f Clin Nutr 1988;42:70914

6 Golden BE, Golden MHN. Plasma zinc and the clinical features of malnutrition. Am f Clin Nutr 1979;32:2390-4.

7 Hambidge KM, Hambidge C, Jacobs M, Baun JD. Low levels of zinc in hair, anorexia, poor growth and hypogeusia in children. Pediatr Res 1972;6:868-74.

8 Roy SK, Tomkins AM. The impact of experimental zinc deficiency on growth, morbidity and ultrastructural devel7.

9 Roy SK, Tomkins AM. Effects of acute repletion of experimental zinc deficiency on intestinal absorption [abstr]. Proceedings of the XIIIth International Congress of Nutrition 1985;C15:139.

10 Roy SK, Drasar BS, Tomkins AM. The impact of zinc deficiency on intestinal response to cholera toxin [abstr]. Proc Nutr Soc 1986;45:39A.

11 Ghisan FK. Transport of electrolytes, water and glucose in zinc deficiency. F Pediatr Gastroenterol Nutr 1984;3:608-12.

12 Moynahan EJ. Acrodermatitis enteropathica: a lethal inherited human zinc deficiency disorder [letter]. Lancet 1974;ii:399-400.

13 Castillo-Duran C, Vial P, Uauy R. Trace mineral balance during acute diarrhoea in infants. F Pediatr 1988;113:452-7.

14 Eckert CD, Hurley LS. Reduced DNA synthesis in zinc deficiency: regional differences in embryonic rats. 7 Nutr 1977;107:855-61.

15 Van Gool JD, Went K, Zegars BJM. Acrodermatitis enteropathica and 22 cellular immune deficiency. Lancet 1976; ;: $1085-7$

16 Castillo-Duran C, Haresi G, Fisberg M, Uauy R. Controlled clinical trial of zinc supplementation during recovery from malnutrition: effects on growth and immune function. $A m$ 7 Clin Nutr 1987;45:602-8.

17 Cunningham-Rundles C, Cunningham-Rundles S, Garofalo $\mathrm{J}$, et al. Increased $\mathrm{T}$ lymphocyte function and thymopoietin following zinc repletion in man [abstr]. Fed Proc 1979;38:1222.

18 NCHS growth charts. Rockville Pike, Maryland: United States Public Health Service, Health Resources Administration (HRA 76-1120, 25,3), 1976

19 Kirkwood B. Essentials of medical statistics. Oxford: Blackwell Scientific Publications, 1988.

20 World Health Organisation. Management of cholera and other acute diarrhoea in adults and children. Geneva: WHO, 1977.

21 Waterlow JC. Classification and definition of protein-calorie malnutrition. BMF 1972;iii:566-9.

22 Golden BE, Golden MHN. Plasma zinc and the clinical features of malnutrition. Am F Clin Nutr 1979;32:2390-4.

23 World Health Organisation. Manual for laboratory investigations of acute enteric infections. Programme for control of tions of acute enteric infections. Programme for control of
diarrhoeal disease CDD/83.3 rev 1. Geneva: WHO, 1987.

24 Solomons NW. On the assessment of zinc and copper nutriture in man. Am 7 Clin Nutr 1979;32:856-71.

25 Sazawal S, Black RE, Bhan MK, Bhandari N, Sinha A, Jalia $S$. Zinc supplementation in young children with acute diarrhoea in India. $N$ Engl $\mathcal{F}$ Med 1995;333:839-44

26 Nelder $\mathrm{CH}$, Hambidge CM. Zinc therapy of acrodermatitis enteropathica. N Engl f Med 1975;292:879-82.

27 Braun OH, Heilman K, Rossner JA, Pauli W, Bergman, KE. Acrodermatitis enteropathica, II: zinc deficiency and ultrastructural finding. Eur $\mathcal{F}$ Pediatr 1977;125:123-62.

28 Roy SK, Behrens RH, Haider R, Akramuzzaman SM, Mahalanabis D, Tomkins AM. Effect of zinc supplementation on intestinal permeability in Bangladeshi children with acute diarrhoea and persistent diarrhoea syndrome. $f$ Pediatr Gastroenterol Nutr 1992;15:289-96.

29 Sachdev HPS, Mittal NK, Mittal SK, Yadav HS. A controlled trial on utility of oral zinc supplementation in acute dehydrating diarrhoea in infants. $\mathcal{F}$ Pediatr Gastroenterol Nutr 1988;7:877-81.

30 Rosado R, Lopez P, Mufioz H, Martinez H, Allen LH. Zinc supplementation reduces morbidity, but neither zinc nor ron supplementation affects growth or body composition of Mexican preschoolers. Am f Clin Nutr 1996;65:13-19.

31 Lethi KA. A study of the effect of zinc supplementation on salivary secretory immunoglobulin A (SIgA) and growth of non breast feeding Amazonian infants. London: London School of Tropical Medicine and Hygiene (University of London), 1982. MSc dissertation.

32 Fenwick PK, Agget PJ, McDonald D, Huber C, Wakelin D. Zinc deficiency and zinc repletion: effect on the response of rats to infection with Strongyloides ratti. Am f Clin Nutr 1990;52:166-72

33 Al-Nakib W, Higgins PG, Barrow I, Batsone G, Tyrell DAJ. Prophylaxis and treatment of rhinovirus colds with zinc gluconate lozenges. F Antimicrob Chemother 1987;20:893-901.

34 Rowland MGM, Cole TJ, Whitehead RG. A quantitative study into the role of infection in determining nutritional status in Gambian village children. Br f Nutr 1977;37:441-1.

35 Golden MHN, Golden BE. Effect of zinc supplementation on the dietary intake, rate of weight gain and energy cost of tissue deposition in children recovering from severe malnutrition. Am f Clin Nutr 1981;34:900-8

36 Simmer K, Khanum S, Carlson L, Thompson RPH. Nutritional rehabilitation in Bangladesh-the importance of zinc. Am $\mathcal{F}$ Clin Nutr 1988;47:1036-40. 